Table 1 PTU-078 Incidence and prevalence of paediatric HPN in Scotland 2003-2010

\begin{tabular}{lcll}
\hline Year & Point prevalence 31.10 & Incident cases & Period prevalent cases \\
\hline 2003 & 9 & 4 & 10 \\
2004 & 5 & 3 & 9 \\
2005 & 6 & 6 & 9 \\
2006 & 7 & 1 & 8 \\
2007 & 4 & 6 & 14 \\
2008 & 8 & 4 & 10 \\
2009 & 11 & 4 & 12 \\
$2010^{*}$ & 11 & 5 & 14 \\
\hline
\end{tabular}

the Scottish HPN MCN; only these centres have facilities and expertise to give prolonged $\mathrm{PN}$ beyond term. Scotland comprises $8.6 \%$ (5.2 million/61 million $\times 100)$ of the paediatric population of the UK. Our aim was to demonstrate nationwide incidence and prevalence of need for paediatric HPN in Scotland, as a representative part of the UK.

Methods The prospective cohort of HPN cases managed in all 4 tertiary paediatric HPN centres in Scotland (Aberdeen, Dundee, Edinburgh and Glasgow) has been ongoing from $01 / 2003$. We reviewed prevalence and incidence of paediatric HPN for each year from 2003 to 2010 (10 months only for 2010), with point prevalence on the $31^{\text {st }}$ of each October. Outcomes of interest included fate - continuing HPN or leaving paediatric network, and reason why.

Results There were 39 HPN cases in this period, with 6 prevalent cases on 01.01.03. There were 33 incident HPN, and 28 of 39 stopped HPN (14 adapted, 2 withdrew, 1 transitioned, 1 left Scotland, and 10 died). Prevalence and incidence data are shown in table 1. *01.01.03-31.10.10 only.

Conclusion We report nationwide data on the incidence and prevalence of paediatric HPN in Scotland, managed in the 4 HPN centres. Extrapolation of our Scottish nationwide data (collected within a national MCN) to the UK ((nx100/8.6)/12 years) suggests that there are annual minimum paediatric incidences and period prevalences of 48 and 126 cases respectively needing HPN in the UK, with an increasing trend in the last 8 years. These data are important for counselling families and for planning regional and national paediatric HPN specialist services in the UK.

Competing interests None.

Keywords home parenteral nutrition, paediatric.

\section{PTU-078 INCIDENCE AND PREVALENCE OF PAEDIATRIC HOME PARENTERAL NUTRITION (HPN): A NATIONWIDE STUDY FROM THE SCOTTISH HPN MANAGED CLINICAL NETWORK}

doi:10.1136/gut.2011.239301.206

A R Barclay, ${ }^{1 *} \mathrm{~J}$ Baxter, ${ }^{2}$ D C Wilson ${ }^{3}{ }^{1}$ Paediatric Gastroenterology, Yorkhill Hospital, Glasgow, UK; ${ }^{2 H P N}$ Managed Clinical Network, Ninewells Hospital, Dundee, UK; ${ }^{3}$ Child Life and Health, University of Edinburgh, Edinburgh, UK

Introduction The four tertiary centres in Scotland providing paediatric ( $<16$ years of age) HPN are formalised within 